\title{
Research on the Cultivation of College Students' Positive Psychological Quality_Research on the Adaptation Strategies of Freshmen
}

\author{
Rui Xu ${ }^{1,}{ }^{*}$, LiJun $\mathrm{Zhao}^{1}$, and JinYang Liu ${ }^{1}$ \\ ${ }^{1}$ Chengdu University of Information Technology, School of Statistics Chengdu, China; E-Mails: 182364860@qq.com
}

\begin{abstract}
Colleges and universities welcome new students every September. After the intense study in high school, the new university life will make the new students feel excited and embarrassed. They are about to face and meet new life, new ways of learning, new classmates and teachers, and so on. Since the new things and environment are very different from those for the new students before they entered the school, we need to pay attention to their psychological changes and promptly channel their psychological problems, otherwise it will cause a lot of psychological discomfort, and maybe it will have some negative impact on the development of various aspects of the follow-up of the new students. It can be seen that it is especially important to grasp the psychological characteristics of students who have just entered the school and to help them develop positive psychological quality, because it not only lays a solid foundation for the mental health education work of colleges and universities, but also promotes the all-round development of students.
\end{abstract}

\section{Common psychological problems of freshman}

When managing freshmen, we conducted a survey on the psychological problems of new students by communicating with new students, conducting questionnaire surveys, and contacting new parents. We found that the following points are psychological problems that are more common among freshmen and cause greater confusion to them.

\subsection{Loneliness}

Freshmen just finished their high school life, bid farewell to their familiar hometown, went to the university campus, faced a new environment, some students did not live in the middle school, did not even leave their parents to live independently, so this strange environment is undoubtedly a big challenge for this part of the students. Judging from the student source of the class I took, there are not many local students in Chengdu, and the proportion of students in the field is large. Some students have experienced living and studying in middle school, but they are away from home to study in an unfamiliar environment with different dialects and foods, which make them feel lonely. According to the work record, a large number of freshmen told me that they have missed their parents at home and their teachers and classmates for a while after entering school. They will compare the classmates around them with their former friends, and they will find that they can't find good friends in the short term. This kind of depressed loneliness is easy to bring negative emotions to freshmen.

\subsection{The confusion of Interpersonal communication}

The students in the university come from all over the country, from different families, and the university is characterized by collective life. A typical example is a dormitory. The four students in a dormitory may have completely different backgrounds. A series of differences in regional culture, ethnicity, living habits, and personality characteristics will inevitably make new students face various interpersonal problems. Freshmen are less likely to have communication skills and methods. When they encounter problems or differences, they first love to find each other's problems, complain about the people and the environment around them. Over time, they think that the university's classmates are difficult to get along with, and even some students are long-term. In such a depressed environment, there will be obstacles to interpersonal communication, which will affect university life and study.

\subsection{Learning pressure}

About the pressure of learning, it is also a relatively common psychological pressure for freshmen to give me feedback. The students told me that the former high school teacher always said, "You can study well in high

\footnotetext{
* Corresponding author: 182364860@qq.com
} 
school and it is easy to go to college." However, after the freshmen contacted the university curriculum, they did not realize the so-called "easy" of the middle school teachers. The learning environment and methods of the university are very different from those of the middle school. Most of the learning in the middle school is carried out under the strict supervision and management of the school and the parents. However, it is well known that the learning environment of the university is relatively open, and the most important feature is autonomy. In the face of difficult, high-demand, collegebased learning, new students lack self-control, or cannot plan and develop their own learning plans and arrangements, these phenomena will make new students worry or even fear of learning. In addition, many freshmen's choice majors are selected with the help of parents. After entering the school, they are very confused about the selected majors, and do not understand the subject characteristics, significance and employment prospects of the majors they are studying. These academic problems also cause a lot of psychological pressure on the new students.

\section{Reasons of the problems}

\subsection{Individual differences of students}

As mentioned before, college freshmen come from different regions and families. From a small living environment and family education, they greatly influence and shape their outlook on life and values, which leads to obvious differences between students. Nowadays, college students have a strong sense of self and tend to be self-centered when encountering practical problems, which will aggravate the occurrence of conflicts. Therefore, freshmen need the correct guidance of counselors. Otherwise, not only will they lack the skills of interpersonal communication in college, but they will also lack the ability to build harmonious interpersonal relationships when they enter the society.

\subsection{Lack of self restraint}

The study in middle school is largely based on the supervision and management of teachers and parents. The purpose of the students' learning is also very simple and clear, that is, they are admitted to the university ${ }^{[1]}$. Once in the university, freshmen go from a strictly managed environment to an seemingly unconstrained environment, they will relax, but this slack is very dangerous, which will make students lack self-control ability, let themselves, do nothing, some students even Transfer your main energy from learning to games, shopping, live streaming, and more. However, when faced with the final exams and various grades, they feel powerless and difficult.

\subsection{The influence of society and one-sidedness of education}

Through communication with some students, I learned that some students are affected by some unhealthy trends in today's society. I feel that colleges don't have to work hard, and a diploma can be mixed. Some students feel that they don't have to go to college because they can't find a high salary after graduation. Work, it is better to play esports games, play live broadcasts and make money fast. Some bad ethos in society can distort students' outlook on life and values. In addition, examoriented education also allows students to pay only attention to academic performance, only care whether they have scored high scores, and ignore the knowledge outside the student school, such as self-care ability, interpersonal skills, self-expression ability, problems encountered. The ability to think, etc., and these comprehensive abilities are the very important ability of students after entering the society. If students only focus on learning, they will also be confused and inferior in the "small society" of the university, which leads to psychological sensitivity and vulnerability.

\section{Cultivate new positive psychological quality}

In order to help new students to adapt to university life faster and better after entering school, to avoid new psychological pressures and problems leading to vicious incidents, college counselors need to strengthen psychological education for new students. The theoretical standards of mental health include cognitive process, emotional process and will process ${ }^{[2]}$. The traditional mental health education of colleges and universities mainly includes the two connotations of mental illness and basic adaptation, but rarely meets the third important indicator of mental health. That is, the concepts of responsibility, diligence, independence, and positiveness. Therefore, in this new environment, in order to better meet the psychological needs of contemporary college freshmen, college counselors can also use the relevant concepts of positive psychological quality under the background of positive psychology under the premise of learning traditional mental health education. Combine it with traditional psychology to achieve the effect of advancing with the times and breaking through innovation.

\subsection{What is the positive psychological quality of college students?}

Positive psychology is a brand new concept of psychology proposed by the famous American psychologists Seligman Sheldon and Laurakin in the late 20 th century. They define positive psychology as "to study the vitality of ordinary people." The science of virtue." Positive psychological quality is an emotion and experience that is not only positive but also persistent. It contains a series of positive quality characteristics such as the ability to love, the way to look at the world positively ${ }^{[3]}$, and positive interpersonal relationships. In short, positive psychological quality pays attention to the study of students' various positive forces, and through 
various specific practical activities and methods, develops and expands these positive forces. The difference between their work focus and traditional mental health education lies in more emphasis on inquiry. Students are inherently motivated and able to develop and improve their positive qualities.

\subsection{The role and importance of positive psychological quality}

Positive psychology is a brand new concept of psychology proposed by the famous American psychologists Seligman Sheldon and Laurakin in the late 20th century. They define positive psychology as "to study the vitality of ordinary people." The science of virtue." Positive psychological quality is an emotion and experience that is not only positive but also persistent ${ }^{[4]}$. It contains a series of positive quality characteristics such as the ability to love, the way to look at the world positively, and positive interpersonal relationships. In short, positive psychological quality pays attention to the study of students' various positive forces, and through various specific practical activities and methods, develops and expands these positive forces. The difference between their work focus and traditional mental health education lies in more emphasis on inquiry. Students are inherently motivated and able to develop and improve their positive qualities.

\subsubsection{Cultivating the psitive psychological quality of new students is of great value in the psychological education of colleges and universities}

The mental health education of colleges and universities in China has some shortcomings compared with some developed countries. For example, the start-up period is in the early stage, and the experience is less. The college counselors lack systematic professional training, onesided education content and outdated education methods. In response to these problems and loopholes ${ }^{[5]}$, the development of mental health education in colleges and universities in China can draw on the excellent experience and practice of developed countries in the West to achieve the purpose of innovation and adjustment. Therefore, colleges and universities in China can use the principles and concepts of positive psychology to explore how to cultivate the positive psychological quality of new students, and through practice, to seek and expand the relevant effective ways to cultivate positive psychological quality, and provide a new mental health education for college freshmen in China. New ideas.

\subsubsection{Cultivating the Positive Psychological Quality of New Students is the Inherent Need of the Comprehensive Development of College Students}

In the process of human evolution, our survival and development require some important driving forces. And these driving forces are our positive qualities. That is to say, positive quality is a psychological element determined by positive genes. The positive behavior of human beings is determined by these active positive psychological elements, and eventually develops into positive psychological characteristics and psychological qualities. In short, having a positive and healthy psychological quality will help college students develop good habits and quality of life, and cultivate their positive attitudes in dealing with things and problems. They will not be discouraged and self-deprecating, so as to develop good habits. It is easier for students to develop happiness in their colleges. Therefore, college students with positive psychological qualities can feel happiness and happiness more easily.

\subsubsection{Cultivate the positive psychological quality of new students and lay a solid foundation for building a harmonious society}

The connotation of creating a harmonious society means not only the stability of the social order, the stability of the state, but also the foundation and, more importantly, the stability of the human heart, that is, people's psychology is more healthy and positive. The rapid development of social economy, the accelerated pace of urban life, bringing progress and convenience ${ }^{[6]}$, but also let humanity face more social pressure and psychological pressure, and these pressures are the initiators of negative emotions. As a successor and successor to the construction of our great motherland, this huge group of college students has an important influence on the development and progress of society. Therefore, cultivating the positive psychological quality of college students can help them to solve problems with various intricate problems and difficulties in life, in learning and in future work, and to internalize these positive psychological qualities. Transforming into a positive force of oneself, forming a habit. Let college students leave the university to enter the society, deal with various problems, reduce the negative impact of social pressure on them, maintain the psychological stability of the people, and thus maintain the stability of our entire society.

\section{How to help new students cultivate positive psychological quality}

Helping freshmen develop positive psychological quality is a systematic work and process that can be grasped from three hands, namely, school, family and students themselves. Parents should establish a positive concept and cooperate with school education. Students should also consciously establish good interpersonal relationships. Here, we should focus on the positive psychological quality of the university students from the school level, that is, as a new counselor.

\subsection{Help students to look at difficulties and frustrations objectively}

Nowadays, most of the college students are only children. In addition to China's fast-developing economic level, 
the quality of life is superior to the past. Contemporary college students lack the experience of arduous environment, which also leads to their ability to withstand stress and withstand setbacks ${ }^{[7]}$. In the face of some difficulties, freshmen can easily show weakness, negative emotions, and even make some excessive behavior. I have encountered a student who made a lot of negative remarks in the QQ space and did not pick up his mother's phone because of the failure of the final exam. His mother was so anxious to call me. Therefore, as a counselor, you can walk into the hearts of students by talking and talking, and help them realize that the difficulty of frustration is only a part of life, because everyone can meet, so you don't have to blame others, and feel that you are not lucky. Moreover, we should teach them that frustration and difficulty are also a challenge or an opportunity in another perspective, because once they succeed in overcoming difficulties and setbacks, college students can learn to grow and become full-fledged. By allowing new students to participate in various practical activities, they will not be afraid of failures and setbacks. In order to better cultivate their willpower to overcome difficulties. It is of great necessity for them to grow up in failure and form a psychological quality that is not afraid of difficulties, help them to look at the world positively, have the ability to love, and lay the foundation for the development of positive psychological quality.

\subsection{Enrich campus culture}

The enrichment of practical activities in colleges and universities can create an active and healthy atmosphere for students. This pleasant campus environment can give students a positive emotional experience and help them form positive psychological qualities. Community activities or other forms of activities in the university require interaction and cooperation between people, which is conducive to students learning to establish good interpersonal relationships, and many activities can greatly enhance students' ability to collaborate, manage, etc. . It is not difficult to find that students who are actively participating in various activities in the class are more outgoing ${ }^{[8]}$, energetic and full of appeal. The environmental factors of colleges and universities are important factors influencing the growth and development of students. Active and interesting cultural and sports activities can not only enrich the campus culture, but also provide students with a warm and positive upward living and learning environment, so that students can form unity. So that students can form unity and the harmonious relationship of friendship, mutual assistance and trust.

\subsection{Promote self-help mental health education}

Helping people to help themselves, as the name implies, encourages students to meet their psychological needs through their own reasonable methods, and reasonably vent their emotions to maintain mental health. When students have a lot of negative emotions, encourage them to talk to teachers, classmates, and friends, learn to apply social support provided by others, and release negative emotions appropriately to relieve psychological stress. What's more, in addition to confessing, students can be recommended to use other methods to control emotions and reduce stress ${ }^{[9]}$, such as going out to exercise, watching a movie of interest, listening to soothing music, and so on. Students should learn to use their own methods to help themselves relax, and gradually develop a positive and healthy attitude. This is an important way for college students to cultivate positive psychological quality.

For students entering colleges and universities, freshman is a crucial period. It is especially important to do mental health work for freshmen. Positive psychology provides a new educational concept and work for ideological and political education and mental health education in ideas of colleges and universities. Helping freshmen develop positive psychological quality, laying a solid psychological foundation for them to quickly integrate and adapt to university life, and it also contributes to build a harmonious campus. At the same time, positive psychological quality also provides a powerful support for students' self-development and social stability after entering the society's help.

\section{References}

1. Michael S. Dunbar,Lisa Sontag-Padilla,Rajeev Ramchand,Rachana Seelam,Bradley D. Stein. Mental Health Service Utilization Among Lesbian, Gay, Bisexual, and Questioning or Queer College Students[J]. Journal of Adolescent Health,2017,61(3).

2. Ahmed M. Abdel-Khalek,David Lester. The association between religiosity, generalized selfefficacy, mental health, and happiness in Arab college students[J]. Personality and Individual Differences, 2017,109.

3. Chrystyna D. Kouros,Megan M. Pruitt,Naomi V. Ekas,Romilyn Kiriaki,Megan Sunderland. Helicopter Parenting, Autonomy Support, and College Students' Mental Health and Well-being: The Moderating Role of Sex and Ethnicity[J]. Journal of Child and Family Studies,2017,26(3).

4. Rosalie Corona,Vivian M. Rodríguez,Shelby E. McDonald,Efren Velazquez,Adriana Rodríguez,Vanessa E. Fuentes. Associations between Cultural Stressors, Cultural Values, and Latina/o College Students' Mental Health[J]. Journal of Youth and Adolescence,2017,46(1).

5. Edmond P. H. Choi,Janet Y. H. Wong,Daniel Y. T. Fong. Mental health and health-related quality of life of Chinese college students who were the victims of dating violence[J]. Quality of Life Research,2017,26(4).

6. Zhang Gaochan. Positive psychological quality training: the important value orientation of psychological education $[\mathrm{J}]$. Jiangsu Education 
College (Social Science Edition), 22, 2: 36-38 (2006).

7. Weng Yubai. How to guide students' psychological barriers in physical education[J]. Education and Teaching Forum, 25 (2011).

8. Chen Yu. The Importance and Effective Ways of College Students' Positive Psychological Quality Cultivation. Journal of Taiyuan University Education College, 33, 3: 17-20 (2015).

9. Chen Yuenan. Discussion on the Ways of Cultivating Positive Psychological Quality of College Students. China Management Informationization, 22, 14: 91-92 (2011). 